\title{
Editorial \\ Colony variability under the spotlight in animal models of arthritis
} John H Robinson

Musculoskeletal Research Group, Institute of Cellular Medicine, Newcastle University, Framlington Place, Newcastle upon Tyne NE2 4HH, UK

Corresponding author: John H Robinson, J.H.Robinson@ncl.ac.uk

Published: 30 April 2009

Arthritis Research \& Therapy 2009, 11:110 (doi:10.1186/ar2653)

This article is online at http://arthritis-research.com/content/11/2/110

(C) 2009 BioMed Central Ltd

See related research article by Farkas et al., http://arthritis-research.com/content/11/1/R21

\begin{abstract}
A recent article by Farkas and colleagues, published in Arthritis Research \& Therapy, is from the laboratory of Dr Tibor Glant and his research team in Chicago, who have investigated in considerable depth the immunopathology of experimental arthritis induced by the major cartilage component proteoglycan aggrecan in an animal model that mimics many features of human rheumatoid arthritis and ankylosing spondylitis. This present report takes our understanding a significant step forward by questioning whether genetic drift in distinct colonies of the same inbred strains of mice has an impact on the parity between data published by different laboratories.
\end{abstract}

In the previous issue of Arthritis Research \& Therapy, Farkas and colleagues [1] compare a large number of colonies of the widely used BALB/c inbred mouse strain; the authors communicate largely good news that substrains vary only modestly in phenotype and the incidence and severity of arthritis.

Confidence in data derived from studying the mechanisms of immunopathology in patients with rheumatoid arthritis (RA) or ankylosing spondylitis is undermined by many variables. One is the genetic diversity of patients in a single cohort or diversity between cohorts studied in different laboratories. Despite a strong association between the expression of certain HLA DR alleles and RA, many additional major histocompatibility ( $\mathrm{MHC}$ ) and non-MHC loci that will differ between individuals are thought to contribute to RA pathogenesis [2]. As a consequence, RA cohorts in studies to date have included patients with a spectrum of disease; it is unlikely, therefore, that a single aetiology will account for disease in all these patients and future studies are likely to segregate patients into distinct disease subsets [3].

The major alternative approach to understanding the pathogenesis of RA avoids these variables by studying the mechanisms of disease in genetically defined animal models. A variety of models of autoimmunity have been developed, each providing a window on some, but not all, aspects of the immunopathology [4]. Of course, animal models have their own drawbacks, such as whether the immune system of the mouse parallels that in human, and how similar the disease processes observed in experimental arthritis are to RA [5]. Received wisdom therefore asserts that a synthesis of the information gleaned from several different animal models, combined with studies possible in RA patients, is likely to lead us forwards in the search for better rational therapies.

In particular, the reductionist approach has been taken by exploiting the genetic homogeneity of inbred mice in which autoimmune arthritis can be induced by synchronised immunisation of groups of animals with single candidate joint autoantigens in adjuvants. The reliable kinetics of the consequent immune response can then be studied in relation to the ensuing RA-like disease pathology. This approach offers the opportunity to observe the sequence of events during disease onset and provides clear answers to questions such as the composition of cellular infiltrates into the synovium and the mechanisms of cartilage and bone destruction.

The most widely studied animal models are collagen-induced arthritis [6] and proteoglycan-induced arthritis (PGIA) [7] in which inflammatory arthritis is induced by immunising genetically susceptible strains of inbred mice, sometimes transgenic for disease-associated HLA alleles or $\mathrm{T}$ cell antigen receptors specific for arthritogenic peptides from joint autoantigens. The best studied autoantigens are the two major cartilage components, type II collagen and proteoglycan aggrecan, both joint autoantigens that induce RA-like disease in mice as well as recall $\mathrm{T}$ cell response in a proportion of RA patients $[8,9]$.

In this context, the article by Farkas and colleagues [1] explores the difference in PGIA in multiple colonies of the

$\mathrm{MHC}=$ major histocompatibility complex; $\mathrm{PGIA}=$ proteoglycan-induced arthritis; $\mathrm{RA}=$ rheumatoid arthritis. 
same inbred strain of mouse, the universally studied BALB/c, which is the most susceptible to PGIA. The goal of the research was to compare the incidence and severity of PGIA and proteoglycan-induced spondylitis and to determine expression patterns of a panel of relevant genes in a large number of distinct colonies of the susceptible mouse strain $B A L B / c$. Although induction of disease by the usual immunisation regime did not reveal any differences in incidence and severity, the sub-lines of BALB/c mice showed modest but significant differences in immune parameters such as cytokine and antibody responses and clinical scores when disease was induced with suboptimal doses of aggrecan, clearly revealing genetic drift in the colonies that affects the immune response and disease pathology.

In conclusion, the present report strengthens the validity of previous studies of the PGIA model in different laboratories, and throws down the gauntlet as a challenge to research groups that use inbred strains of mice as models for other human diseases, particularly in cases when groups have published contradictory data.

\section{Competing interests}

The author declares that they have no competing interests.

\section{References}

1. Farkas B, Boldizsar F, Tarjanyi O, Laszlo A, Lin SM, Hutas G, Tryniszewska B, Mangold A, Nagyeri G, Rosenzweig HL, Finnegan A, Mikecz K, Glant TT: BALB/c mice genetically susceptible to proteoglycan-induced arthritis and spondylitis show colonydependent differences in disease penetrance. Arthritis Res Ther 2009, 11:R21.

2. Oliver JE, Worthington J, Silman AJ: Genetic epidemiology of rheumatoid arthritis. Curr Opin Rheumatol 2006, 18:141-146.

3. van der Helm-van Mil AH, Huizinga TW: Advances in the genetics of rheumatoid arthritis point to subclassification into distinct disease subsets. Arthritis Res Ther 2008, 10:205.

4. Holmdahl R: Dissection of the genetic complexity of arthritis using animal models. Immunol Lett 2005, 103:86-91.

5. Rosenthal N, Brown S: The mouse ascending: perspectives for human-disease models. Nat Cell Bio/ 2007, 9:993-999.

6. Brand DD, Kang AH, Rosloniec EF: Immunopathogenesis of collagen arthritis. Springer Semin Immunopatho/ 2003, 25:3-18.

7. Glant TT, Finnegan A and Mikecz K: Proteoglycan aggrecaninduced arthritis: Immune regulation, cellular mechanisms and genetics. Crit Rev Immunol 2003, 23:199-250.

8. Kim HY, Kim WU, Cho ML, Lee SK, Youn J, Kim SI, Yoo WH, Park JH, Min JK, Lee SH, Park SH, Cho CS: Enhanced T cell prolidferative response to type II collagen and synthetic peptide CII (255-274) in patients with rheumatoid arthritis. Arhtritis Rheum 1999, 42:2085-2093.

9. Zou J, Zhang Y, Thiel A, Rudwaleit M, Shi S-L, Radbruch A, Poole $\mathrm{R}$, Braun J, Sieper J: Predominnant cellular immune response to the cartilage autoantigenic G1 aggrecan in ankylosing spondylitis and rheumatoid arthritis. Rheumatology 2003, 42: 846-855. 